\title{
A Mixed-Integer Linear Programming Model for Transportation Planning in the Full Truck Load Strategy to Supply Products with Unbalanced Demand in the Just in Time Context: A Case Study
}

\author{
Julien Maheut and Jose Pedro Garcia-Sabater \\ ROGLE - Departamento de Organización de Empresas, Universitat Politècnica de Valéncia, \\ Camino de Vera S/N, 46022 Valencia, Spain \\ juma2@upv.es, jpgarcia@omp.upv.es
}

\begin{abstract}
Growing awareness in cutting transport costs and minimizing the environmental impact means that companies are increasingly interested in using the full truck load strategy in their supply tasks. This strategy consists of filling trucks completely with one product type or a mixture of products from the same supplier. This paper aims to propose a mixed-integer linear programming model and procedure to fill trucks which considers limitations of stocks, stock levels and unbalanced demand and minimization of the total number of trucks used in the full truck load strategy. The results obtained from a case study are presented and are exported in a conventional spreadsheet available for a company in the automotive industry.
\end{abstract}

Keywords: Supply Chain Management, Automotive Industry, Full Truck Load, Case Study.

\section{Introduction}

In an increasingly globalized and internationalized world, Supply Chains (SCs) have had to adapt to remain competitive and become constantly more efficient, agile and flexible. SCs, and more specifically, all the companies involved in it, face a new problem: increasing complexity in managing products and in planning operations.

Increasing the variety of products manufactured or offered to customers directly influences planning tasks, currently deployed management methods and all the processes carried out to deliver the finished good. For example, models or tools designed and optimized for a definite and characteristic situation may no longer prove efficient and/or effective when product variety widens.

Increased complexity is one of the most difficult challenges for those companies currently working in tight environments because stocks are seen as wasteful and unnecessary costs if they exceed certain safety stock levels or coverage levels on days of demand, known as run-out time; that is, run-out time is the stocks coverage level of a specific product [1]. The proper calculation of these values is not only highly relevant 
when demand is irregular or when various products with short life cycles have different demand levels, but can be essential when demand is uncertain; this is precisely the case of the current economic crisis.

In the literature, the effect of variety on production planning, scheduling and the costs involved is a relatively developed theme [2]. Nonetheless, effects on transport tasks (shipping or supplying) have not been as well addressed to the best of our knowledge. Transportation planning is often approached from three perspectives and different backgrounds: strategic transport planning, tactical transport planning and operational transport planning.

At the operational level, the literature presents and identifies two main problem classifications: routing and truck-loading problems. However, the size of truck shipments may also be considered: partial shipments problems, less than truckload (LTL) shipments problems and full truck load (FTL) shipments problems. Historically, the automotive industry has used milk runs to resolve collection routes. Moreover, crossdocking systems [3] and, obviously, direct full load shipments [4] are also used.

Typically at the operational level, automotive assembly plants employ three different strategies to coordinate supply strategies [5]. Suppliers that supply low-volume products can receive direct shipments from a single supplier following the LTL strategy. Alternatively, shipments from multiple suppliers can be consolidated using milk runs in the LTL or the FTL strategy.

These three strategies are usually fixed according to the supplier because supply transport capacity contracts in the automotive sector are long-term contracts. They reserve a fixed transport capacity in each horizon and the carrier has to pay a fixed amount during each period, which is completely independent of the use of trucks. This long-term contracts policy is changing with new social conditions and environmental standards. For instance, optimizing fleet use has become one of the most important measurable performances.

In order to cut costs and minimize the environmental impact, the general trend in the automotive industry has been to reduce the number of actors in its own SC [6]. These SCs' first-tier companies have attempted to move toward a single supplier per product family. The direct consequence is that supply logistics has shifted toward the FTL strategy in which each provider supplies multiple products. The full-filling trucks problem has been traditionally solved with the help of a personalized, customized spreadsheet [4]. Moreover the "follower", which is the supplier contact, is responsible for planning and supervising truck loads; moreover, it is usually responsible for determining stock levels on both sides of the SC.

Each follower's working method might differ even within the same company as it takes into account not only actual product characteristics, but also different vehicle characteristics. With increasing product variety, which can form a product mix within a truck, the manual working method quickly reaches its limit and does not meet company expectations.

To overcome these problems, the literature offers a range of proposed solutions [7]. As Goetschalckx states in [8], Ford Motors Company and General Motors use fullsize pickup truck models, but they are not described. In the automotive sector, the FTL strategy led to overdeliveries (serve in advance), as stated Garcia-Sabater et al. [4] in the case of motors distribution planning. Liu et al. [9] present 2-phase heuristic algorithms for the full truckloads multi-depot capacitated vehicle routing problem in 
carrier collaboration, but the consideration of different packaging for different products is not considered. Arunparam et al. [10] propose an algorithm for solving an integer-programming formulation of this vehicle-routing problem with full truckloads, but as in [9], a complex routing problem is considered. In the literature review, Boysen and Fliedner [3] offer an interesting literature review about cross-docking problems, but in our case study, only direct shipment by the FTL strategy must be considered. To the best of our knowledge, an MILP model for procurement planning that considers packaging and the FTL strategy which contemplates loss of truck capacity has never been proposed because of product mixture in the same truck. Other concerns in the automotive industry that our model includes are stocks limitations (minimum/maximum run out-times and total stock limits). These limitations in conjunction with stock levels, unbalanced demand and minimizing the total number of trucks used in the FTL strategy have never been considered, which implies a substantial combination of products to overcome truck capacity problems. This is precisely the aim of this paper: to propose an MILP that completes these types of trucks. Considerations such as time windows, routing and different truck capacities are not contemplated.

The rest of the paper is organized as follows. Section 2 offers a detailed description of the problem study. Section 3 proposes hypotheses to solve the problem, and then presents a mixed-integer linear programming (MILP) model to solve the problem. Section 4 presents a case study. Finally, the last section includes conclusions and future research lines.

\section{Problem Description}

An engine assembly plant is not only constituted by the assembly line of engines, but also by five component production lines. These lines constitute the so-called 5Cs (cylinder blocks, cylinder heads, camshafts, crankshafts, connecting rods). To produce these finished components, raw materials, whose origins are foundries, are produced in considerably large-sized batches. This raw material has to be purchased from suppliers and adjusted because the plant cannot hold substantial stock levels of materials at the entrance of component production lines.

The problem lies in deciding how to load the truck arriving from each supplier for the purpose of minimizing the total number of trucks over the year to keep the total stock below a maximum level and to also consider at least two alternative constraints:

- Maintaining a certain number of days of stock (called run-out time in days of demand) of raw material and a minimum safety stock for all the products.

- Considering maximum run-out times for products and considering stock restrictions because of limited storage capacity. This run-out time can be a maximum products demand peak, but also the stored holding value of the products controlled by the finance department.

Other considerations are taken into account. Because of paper's length restriction, those are not present in this extended abstract. 


\section{$3 \quad$ Modeling the Problem}

\subsection{Hypothesis}

Product consumption is known and detailed for each period of the horizon. All the costs are assumed linear and known. The capacity of racks and all the trucks is also known. To avoid complicating the model presented herein, the same capacity for all trucks has been considered. Minimum and maximum run-out times are considered at all times for all products, or minimum and maximum stock levels values are determined by users and the respective stakeholders.

While minimizing costs and ensuring the planned run-out time, the following goals are pursued:

- Reducing the total number of trucks used during the horizon.

- Reducing capacity penalties.

- Reducing the level of obsolescence of the products in stock.

Penalties depend on the mixture of products loaded, but simplification is considered: from two different products loaded onto a truck, truck capacity will decrease by one unit for each new separate product loaded.

It is assumed that the truck should be completely filled with racks of products after taking into account the capacity loss due to the mixture of products. The minimum coverage defined must be guaranteed and cannot exceed the maximum coverage in days of demand.

The next section presents the mathematical MILP model which solves this problem.

\subsection{MILP Model}

\section{Data Input Notation}

The MILP model is specified as follows.

Table 1. Indexes and sets

\begin{tabular}{cl}
\hline$i \in P=\left\{1, \ldots, n_{p}\right\}$ & Products \\
$t=1, \ldots, T$ & Periods (in day units) \\
$j \in J$ & Trucks \\
\hline
\end{tabular}

Table 2. Parameter notation (1)

\begin{tabular}{cl}
\hline$D_{i t}$ & Demand of product $i$ on day $t$ \\
$R_{i}$ & Number of products $i$ that can be loaded in a rack \\
$Y_{i}$ & Initial stock level of product $i$ \\
$K_{j}$ & Load capacity of truck $j$ \\
$s_{i} / S_{i}$ & Minimum/Maximum desired stock level of product $i$ \\
$\frac{\mathrm{cob}_{i} / \overline{c o b_{i}}}{M}$ & Minimum/Maximum run-out times of product $i$ (in day units) \\
\hline$C^{\alpha}$ & Large number \\
$C^{\delta}$ & Setup costs for using a truck \\
$C^{\lambda}$ & Penalty costs for a truck's loss of capacity \\
\hline
\end{tabular}


In modeling terms, we need to define two parameters:

- The maximum number of trucks available on day $t$.

- The run-out time for one product.

As this last parameter takes a different value to the minimum and maximum desired stocks levels for each product, a procedure to calculate a single parameter that fixes the minimum and maximum levels for each product in each period $\left(S M_{i t} / \overline{S M_{i t}}\right)$ has been created.

Table 3. Variable notation

\begin{tabular}{cl}
\hline$y_{i t} \in \mathbb{Z}^{+}$ & Stock level of product $i$ on day $t$ \\
$v_{i j t} \in \mathbb{Z}^{+}$ & Number of products $i$ loaded onto truck $j$ on day $t$ \\
$\alpha_{j t}$ & $=1$ if truck $j$ is used on day $t$ ( 0 otherwise $)$ \\
$\lambda_{t} \in[0,1]$ & Minimum level of balanced stock of all the products on day $t$ \\
$\delta_{i j t}$ & $=1$ if one product $i$ is loaded onto truck $j$ on day $t(0$ otherwise $)$ \\
$\varepsilon_{j t} \in \mathbb{Z}^{+}$ & Variable that counts the number of the different variants loaded \\
\hline
\end{tabular}

\section{Objective Function}

The objective of the proposed model is to minimize total supply costs.

$$
\begin{gathered}
Z=\operatorname{Min}[\text { Costs }] \\
\text { Costs }=\sum_{t} \sum_{j} \alpha_{j t} \cdot C^{\alpha}+\sum_{t} \sum_{j} C^{\delta} \cdot\left(\varepsilon_{j t}-1\right)+\sum_{t} \lambda_{t} \cdot C^{\lambda}
\end{gathered}
$$

The objective function (1), which consists in minimizing total supply costs, may be approximated as a linear function (2).

\section{Constraints}

$$
\begin{gathered}
y_{i, 0}=Y_{i}, \forall i \\
y_{i t}=y_{i, t-1}-D_{i t}+\sum_{j} v_{i j t}, \forall(i, t) \\
\underline{S M_{i t} \leq y_{i t} \leq \overline{S M_{i t}}, \forall(i, t)}
\end{gathered}
$$




$$
\begin{gathered}
\left(1-\lambda_{t}\right) \leq \frac{\overline{S M_{i t}}-y_{i t}}{\overline{S M_{i t}}-\underline{S M_{i t}}}, \forall(i, t) \\
v_{i j t}-M \cdot \delta_{i j t} \leq 0, \forall(i, j, t) \\
\sum_{i} \delta_{i j t} \leq \varepsilon_{j t}, \forall(j, t) \\
\varepsilon_{j t} \geq 1, \forall(j, t) \\
K_{j} \cdot \alpha_{j t}-\left(\varepsilon_{j t}-1\right)=\sum_{i} \frac{v_{i j t}}{R_{i}}, \forall(j, t)
\end{gathered}
$$

The initial inventory levels of products are known (3). Classical continuity constraints (4) apply to the model. The stock level reached at the end of a period must be above a minimum level without exceeding a maximum level (5). Balancing stock levels is determined as a percentage according to the values of the stock level limits (6). With Constraint (7), we know if product $i$ is loaded onto truck $j$ on day $t$. Constraints (8) and (9) determine the number of variants loaded and the penalties associated with each truck used. Finally with Constraint (10), it is assumed that a truck's capacity in racks less its capacity penalty equals the racks loaded onto a truck.

\section{Case Study}

This study was particularly motivated by the problem faced by a company which assembles motors in Spain and sends its end products all over the world. The complete case study is presented in [4], but the 4 week procurement model had to evolve because stakeholders needed to consider new considerations like penalty for loss of capacity and the different run out-times of products. Given length constraints, a simple case study will be evaluated: five time periods, four products and three trucks will be considered. The different costs are: $\mathrm{C}^{\alpha}=60, \mathrm{C}^{\delta}=100, \mathrm{C}^{\lambda}=1000$. Tables 4 and 5 present the parameter values of the case study.

Table 4. Parameter values (I)

\begin{tabular}{|c|c|c|c|c|c|c|} 
Product & $R$ & $Y$ & $S$ & $S$ & $\underline{c o b}$ & $\overline{c o b}$ \\
\hline 1 & 8 & 160 & 150 & 300 & 1 & 2 \\
2 & 6 & 100 & 0 & 200 & 2 & 6 \\
3 & 8 & 0 & 0 & 50 & 2 & 6 \\
4 & 7 & 50 & 50 & 100 & 1 & 2
\end{tabular}


Table 5. Parameter values (II)

\begin{tabular}{c|c|c|c|c} 
Period & Product & $D$ & $\underline{S M}$ & $\overline{S M}$ \\
\hline 1 & 1 & 150 & 186 & 300 \\
1 & 2 & 80 & 0 & 157 \\
1 & 3 & 0 & 14 & 50 \\
1 & 4 & 50 & 51 & 100 \\
2 & 1 & 186 & 181 & 300 \\
2 & 2 & 0 & 0 & 157 \\
2 & 3 & 14 & 0 & 50 \\
2 & 4 & 51 & 52 & 100 \\
3 & 1 & 181 & 155 & 300 \\
3 & 2 & 0 & 78 & 157 \\
3 & 3 & 0 & 0 & 50 \\
3 & 4 & 52 & 59 & 100 \\
4 & 1 & 155 & 170 & 300 \\
4 & 2 & 78 & 79 & 200 \\
4 & 3 & 0 & 15 & 50 \\
4 & 4 & 59 & 64 & 100 \\
5 & 1 & 170 & 150 & 300 \\
5 & 2 & 79 & 0 & 200 \\
5 & 3 & 15 & 0 & 50 \\
5 & 4 & 64 & 50 & 100
\end{tabular}

Table 6. Results

\begin{tabular}{|c|c|c|c|} 
PRODUCT & TRUCK & PERIOD & $\mathrm{v}$ \\
\hline 4 & 1 & 1 & 98 \\
1 & 1 & 2 & 112 \\
1 & 1 & 4 & 48 \\
4 & 1 & 4 & 49 \\
1 & 2 & 1 & 112 \\
1 & 2 & 2 & 112 \\
2 & 2 & 3 & 84 \\
4 & 2 & 4 & 98 \\
1 & 2 & 5 & 40 \\
4 & 2 & 5 & 56 \\
1 & 3 & 1 & 74 \\
3 & 3 & 1 & 30 \\
2 & 3 & 2 & 72 \\
4 & 3 & 2 & 7 \\
1 & 3 & 3 & 112 \\
1 & 3 & 4 & 112 \\
1 & 3 & 5 & 112
\end{tabular}

This model is solved by employing Gurobi Optimiser 4.5. The results show an average running time of 305 seconds per instance using an Intel Core i7 $3.22 \mathrm{GHz}$ processor, 24 GB RAM and Windows 7 as the OS. The procurement planning results are presented in Table 6.

As seen in the results, not all the trucks are needed in each period. Thanks to the procurement plan, we can see how capacity loss is considered and that each truck is fully loaded. Nevertheless, while implementing the real industry tool, the use of the MILP model is limited because computational times prolong exponentially when product and period numbers increase.

\section{Conclusions}

This paper presents an MILP model for planning supply planning in an engine assembly plant. The planning model allows different run-out times of products based on their fundamental characteristics and the arrival of loaded trucks in the FTL strategy by considering unbalanced run-out time to cover any changes in production planning and stock limits, plus truck capabilities which are penalized according to their load. A simple case study is proposed to demonstrate the applicability of the model.

A future research line would be to identify other strategies for loading trucks and to evaluate the best strategy in terms of transport costs against holding costs using real data. Another future research line would be to determine the minimum run-out time to be maintained in case of data uncertainty.

Acknowledgements. The work described in this paper has been partially supported by the Spanish Ministry of Science and Innovation within the Program "Proyectos de Investigación Fundamental No Orientada through the project "CORSARI MAGIC DPI2010-18243" and through the project "Programacion de produccion en cadenas de suministro sincronizada multietapa con ensamblajes/desemsamblajes con 
renovacion constante de productos en un contexto de inovacion DPI2011-27633". Julien Maheut holds a VALi+d grant funded by the Generalitat Valenciana (Regional Valencian Government, Spain) (Ref. ACIF/2010/222).

\section{References}

1. Bitran, G.R., Haas, E.A., Hax, A.C.: Hierarchical production planning: a single stage system. Operations Research 29, 717-743 (1981)

2. Sun, H., Ding, F.Y.: Extended data envelopment models and a practical tool to analyse product complexity related to product variety for an automobile assembly plant. International Journal of Logistics Systems and Management 6, 99-112 (2010)

3. Boysen, N., Fliedner, M.: Cross dock scheduling: Classification, literature review and research agenda. Omega 38, 413-422 (2010)

4. Garcia-Sabater, J.P., Maheut, J., Garcia-Sabater, J.J.: A two-stage sequential planning scheme for integrated operations planning and scheduling system using MILP: the case of an engine assembler. Flexible Services and Manufacturing Journal 24, 171-209 (2012)

5. Ben-Khedher, N., Yano, C.A.: The Multi-Item Replenishment Problem with Transportation and Container Effects. Transportation Science 28, 37-54 (1994)

6. Cousins, P.D.: Supply base rationalisation: myth or reality? European Journal of Purchasing Supply Management 5, 143-155 (1999)

7. Kiesmüller, G.P.: A multi-item periodic replenishment policy with full truckloads. International Journal of Production Economics 118, 275-281 (2009)

8. Goetschalckx, M.: Transportation Systems Supply Chain Engineering, vol. 161, pp. 127-154. Springer, US (2011)

9. Liu, R., Jiang, Z., Fung, R.Y.K., Chen, F., Liu, X.: Two-phase heuristic algorithms for full truckloads multi-depot capacitated vehicle routing problem in carrier collaboration. Computers Operations Research 37, 950-959 (2010)

10. Arunapuram, S., Mathur, K., Solow, D.: Vehicle Routing and Scheduling with Full Truckloads. Transportation Science 37, 170-182 (2003) 